\title{
Evidence for a decadal-scale decline in the growth rates of juvenile scleractinian corals
}

\author{
Peter J. Edmunds* \\ Department of Biology, California State University, 18111 Nordhoff Street, Northridge, California 91330-8303, USA
}

\begin{abstract}
Juvenile life stages play critical roles in the population dynamics of virtually all organisms, and therefore precise estimates of juvenile growth and survival are important for accurate demographic analyses. For tropical reef corals, the contribution of juveniles to population dynamics is strongly determined by their growth rates, which are inversely proportional to the duration of this life stage and the risks of mortality, yet empirical estimates of this important trait are surprisingly rare. Based largely on results published before 1990, it is often assumed that juvenile corals $\leq 50 \mathrm{~mm}$ diameter grow $\sim 10$ to $34 \mathrm{~mm} \mathrm{yr}^{-1}$, and therefore are $\sim 1.5$ to $5.0 \mathrm{yr}$ old. In contrast, results presented here show that juvenile corals ( $\leq 40 \mathrm{~mm}$ diameter) in St. John, US Virgin Islands, have grown at much slower rates on shallow reefs ( $<9 \mathrm{~m}$ depth) where annual censuses have been completed for 9 yr (1996 to 2005). For nearly a decade, juvenile corals in this location have maintained overall mean growth rates of only $3 \mathrm{~mm} \mathrm{yr}^{-1}$, or $6 \mathrm{~mm} \mathrm{yr}^{-1}$ for the subset of colonies that grew $\geq 0 \mathrm{~mm} \mathrm{yr}^{-1}$. Therefore, most of these juvenile corals have grown at rates consistent with an upper age estimate of 7 to $13 \mathrm{yr}$, which is 1.4 to 8.7 times older than estimates derived from often-cited growth rates. This discrepancy has important implications, because it suggests that the recruitment dynamics of coral populations may function over time scales longer than are usually considered. Conceivably, these time scales may now extend over lengthier periods than once was the case, at least as can be determined from sparse results distributed through $>32 \mathrm{yr}$ of peer-reviewed studies that reveal a gradual decline in the growth rates of juvenile corals. The correspondence of this decline with rising seawater temperature and depressed aragonite saturation state raises the possibility that the effects of global climate change have already reduced the growth of juvenile corals.
\end{abstract}

KEY WORDS: Corals · Scleractinia $\cdot$ Juveniles $\cdot$ Recruits Growth - Climate change

Resale or republication not permitted without written consent of the publisher

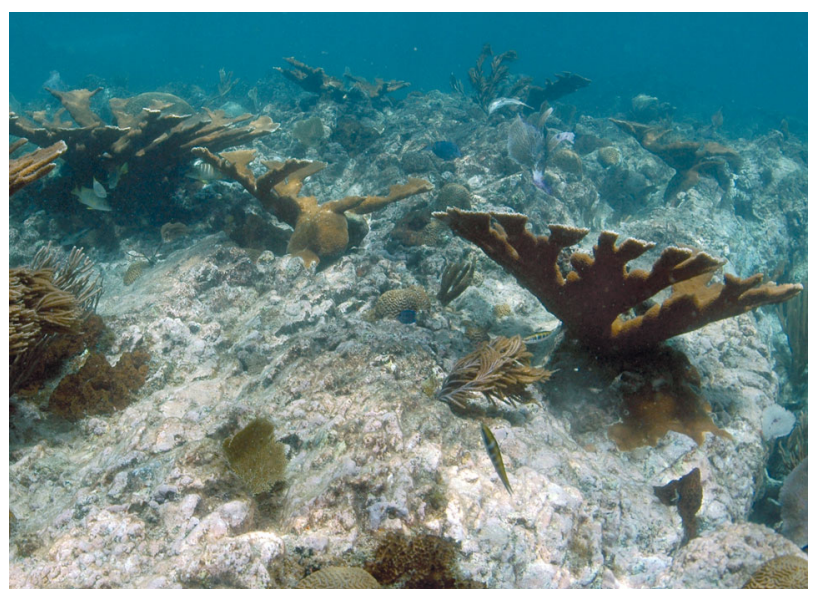

Coral reef off St. John, US Virgin Islands, where juvenile corals have been found to grow more slowly than expected.

Photo: P. Edmunds

\section{INTRODUCTION}

Demographic analyses provide important tools for ecologists working to understand the causes of changing population sizes (Caswell 2001), and the raw material for such studies typically are the fates of individual organisms, which can be challenging data to collect. The marine environment poses particular problems in this regard, for marine organisms often can be difficult to observe, and for benthic taxa that frequently have pelagic larvae (Thorson 1950), some of the critical life stages (i.e. larvae and newly settled recruits) can be the hardest to quantify. As a result, the demographic parameters for these life stages are prone to bias, and when applied to the numerous marine taxa that produce vast numbers of pelagic larvae and newly settled 
recruits (Thorson 1950, Morgan 2001), small variations in traits like larval settlement and juvenile survivorship can have large effects on population projections (Underwood \& Keough 2001).

The ability to model population dynamics is highly relevant to coral reefs, where there is an urgent need to place the declining health of these ecosystems (Hughes et al. 2003, Bellwood et al. 2004) in a demographic context equating coral death with the rate at which corals recruit and the likelihood that they survive to an adult stage (Hughes \& Tanner 2000, Edmunds \& Elahi 2007). One facet of the 'coral reef crisis' (Bellwood et al. 2004) is the contrast between contemporary literature that is dominated by examples of reefs that have lost large amounts of coral cover (Gardner et al. 2003, Bellwood et al. 2004) which has usually failed to grow back (Hughes 1994, Gardner et al. 2005, Rogers \& Miller 2006), and older studies that typically assume that reef recovery occurred (Connell 1978, Pearson 1981, Karlson \& Hurd 1993). Faced with evidence that 20 to $40 \mathrm{yr}$ ago reefs did indeed recover from disturbances (e.g. Pearson 1974, 1981, Hunter \& Evans 1995, Connell 1997), a critical question is whether there has been a decline in the ability of coral communities to recover from disturbances (Nystrom et al. 2000, Bellwood et al. 2004), and if so, what are the underlying mechanisms that have reduced the ability of corals to recover? This study addresses one component of such mechanisms, namely the growth of juvenile colonies.

While fragmentation can play an important role in population maintenance for some coral species (Highsmith 1982), the primary mechanism of recovery for coral communities following severe disturbances is larval settlement and recruitment (Harrison \& Wallace 1990, Richmond 1997), and accordingly these processes have enjoyed a long history of research attention (Harrison \& Wallace 1990). Some investigations have quantified coral recruitment (i.e. the appearance in the population of the smallest detectable individual, sensu Caley et al. 1996) (e.g. Dunstan \& Johnson 1998, Hughes et al. 1999), while others have focused on small colonies that are young relative to adults (Bak \& Engel 1979), and usually sexually immature (i.e. juveniles; Soong 1991). The quantification of juveniles rather than recruits usually results in a more tractable experimental system, but important limitations of this approach are that it precludes an evaluation of post-settlement processes that occur during an early fraction of the time occupied by the young age class (Gosselin \& Qian 1997, Hunt \& Sheibling 1997), and relies on the assumption that some of the juveniles will reach an adult stage. This assumption clearly is valid, as demonstrated by the persistence of coral populations, post-settlement survivorship over the first
3 to 12 mo of 16 to $71 \%$ (Babcock 1985), and typical annual survivorships for juvenile corals of 0 to $77 \%$ (Smith 1992, 1997, Wittenberg \& Hunte 1992, Edmunds 2000). However, the biological significance of annualized survivorships for juvenile corals depends on the longevity of this life stage, and in large part, this is determined by growth rates. With constant survivorship, the number of corals leaving the juvenile stage is inversely related to the time spent in this life stage. For juvenile corals, the best estimates of the duration of this life stage come either from cohort analyses, where the proportion of colonies growing out of the juvenile stage is determined for a fixed interval of time (Hughes 1984, Fong \& Glynn 1998, Hughes \& Tanner 2000), or through the direct measurement of size over time (e.g. Van Moorsel 1985, 1988, Babcock 1991). In both cases, surprisingly few data are available.

The research described in this paper was completed against the backdrop of an ongoing need for measurements of the growth and longevity of juvenile corals, and the initial concept was strengthened by an earlier analysis from St. John, US Virgin Islands (Edmunds 2000), that showed that juvenile corals grow slowly compared to rates often cited in the literature (Bak \& Engel 1979, Van Moorsel 1985, 1988). Given the importance of growth in determining the contribution of juvenile corals to population dynamics, there are important implications for overestimating growth rates (Babcock 1985), notably in misconstruing the tempo of population change, and upwardly biasing the rates at which coral populations are thought to recover from disturbances. The goals of the present study were first, to quantify the growth of juvenile corals over a lengthy period in order to evaluate the average growth rates and the variance around these values, and second, to compare these results to previously published rates as a test for possible long-term changes in growth rates of juvenile corals. To achieve these goals, the growth of juvenile corals was measured annually for nearly a decade on the shallow reefs of St. John, with the outcome demonstrating that they grow more slowly than previously was thought, at least on shallow reefs in one Caribbean location, and perhaps more slowly than was recorded 20 to $30 \mathrm{yr}$ ago.

\section{MATERIALS AND METHODS}

Starting in 1996, the growth of juvenile corals has been measured as part of a long-term monitoring program along the south coast of St. John (described in detail in Edmunds 2002, 2004, 2006, Edmunds \& Elahi 2007; see also Rogers \& Beets 2001, Rogers \& Miller 2006). The reefs in this location are protected within the Virgin Islands National Park and Biosphere Reserve, 
and most of the fringing reefs in shallow water $(<9 \mathrm{~m}$ depth) are dominated by granitic substratum. Because this rock is relatively smooth with $<10 \%$ cover of scleractinians (Edmunds 2002), juvenile corals are easier to locate on these surfaces in comparison to more rugose habitats with higher coral cover (Edmunds 2000, 2004). Juvenile corals were defined as colonies ranging in size from the smallest that could be detected $(\sim 2 \mathrm{~mm}$ diameter) to $40 \mathrm{~mm}$ diameter, and only colonies with near-circular outlines were selected in order to avoid asexual recruits that usually have fractured margins. Within this size range, the smallest colonies could not be identified reliably to species, and therefore most corals were identified to genus. Corals were scored to species in 2 cases, Favia fragum and Siderastrea radians, which differ from other small corals because they can attain sexually maturity at $\leq 40 \mathrm{~mm}$ diameter (Soong 1991), and therefore potentially are adults. In these 2 cases, species-level identification was possible because there is only one species in the genus Favia, and $S$. radians has a distinct morphology, even when small. In the case of Siderastrea, which is represented by only 2 species in this location, identification of $S$. radians identified the remainder as $S$. siderea, which typically accounted for about $33 \%$ of the juvenile Siderastrea on the study reefs.

The growth of juvenile corals was determined by tagging and measuring small corals at 6 sites between Cabritte Horn and White Point (described in Edmunds 2002,2004 ). Five of the sites are at $5 \mathrm{~m}$ depth, and one at $9 \mathrm{~m}$ depth, and were characterized by similar habitats. Juvenile corals were selected haphazardly for tagging along permanently marked transects, and small colonies of all species were tagged by gluing a numbered aluminum tag to the adjacent rock with epoxy (Z-Spar A788).

The tagged corals were measured with calipers $( \pm 0.1 \mathrm{~mm})$, and their size was determined from the mean of the 2 major diameters at the base of the living tissue. One year later, the tagged corals were assessed for condition (alive or dead) and, if alive, again were measured; growth rates were calculated as the change in mean diameters. In the first 3 yr of the study (1996 to 1998) the juvenile corals were surveyed annually in May, but for the remaining 6 yr the surveys were completed in August. Because the number of tagged corals declined over each period due to growth out of the desired size range (i.e. $\leq 40 \mathrm{~mm}$ ), mortality (14 to $46 \% \mathrm{yr}^{-1}$; P. J. Edmunds unpubl. data), and tags that could not be found (usually when they became encrusted with coralline algae), additional corals were tagged every year. The number of tags that could not be found, and the time available for tagging new corals varied among years, and therefore the sample sizes (i.e. number of tagged corals) for growth estimation were not constant. Although the taxonomic composition of the tagged corals varied from year to year, the taxa most frequently tagged and found again after 1 yr were Porites, Agaricia, Favia, Diploria and Siderastrea radians (Table 1).

Growth rates of colony mean diameter were expressed as $\mathrm{mm} \mathrm{yr}^{-1}$ and calculated first, from all of the corals (i.e. regardless of whether they increased or decreased in size), and second, from corals that grew $\geq 0 \mathrm{~mm} \mathrm{yr}^{-1}$; corals that were recorded as decreasing in size typically were characterized by tissue that no longer extended to the basal margin of the skeleton. These 2 methods were used to gain insight into the difference between the lower 'realized' growth rates and the higher 'potential' growth rates that are less biased by tissue shrinkage. The rationale for this approach was that shrinkage resulted from a variety of processes, some of which represented the catabolism of biomass, and some that represented extrinsic processes (e.g. predation, competition, and grazing). While tissue catabolism reflects a deficit of energy obtained through feeding (Sebens 1981), and therefore is a facet of growth, shrinkage due to extrinsic processes typically is decoupled functionally from growth. The relative importance of catabolism and extrinsic processes in driving the reduction in size could not be determined, and therefore a technique was applied through which many of the corals that shrank could be excluded. With this approach, it is not possible to be certain that growth rates $\geq 0 \mathrm{~mm} \mathrm{yr}^{-1}$ were unaffected by shrinkage, and therefore the potential growth rates are probably conservative. To determine the extent to which the estimates of growth rates for juvenile corals were biased by the likely inclusion of sexually mature colonies (i.e. adults) of Favia and Siderastrea radians, growth rates for all juveniles were compared to the

Table 1. No. of juvenile corals tagged and remeasured $1 \mathrm{yr}$ later in the 9 yr period 1996 to 2005. Values shown for the most frequently tagged taxa. Others: juvenile corals in other taxa or unidentifiable. S.: Siderastrea

\begin{tabular}{|lcccccc|}
\hline Years & $\begin{array}{c}\text { Porites } \\
\text { (n) }\end{array}$ & $\begin{array}{c}\text { Agaricia } \\
\text { (n) }\end{array}$ & $\begin{array}{c}\text { Favia } \\
\text { (n) }\end{array}$ & $\begin{array}{c}\text { Diploria } \\
\text { (n) }\end{array}$ & $\begin{array}{c}\text { S. radians } \\
\text { (n) }\end{array}$ & $\begin{array}{c}\text { Others } \\
\text { (n) }\end{array}$ \\
\hline $1996-1997$ & 56 & 34 & 66 & 13 & 58 & 22 \\
$1997-1998$ & 21 & 13 & 23 & 10 & 29 & 3 \\
$1998-1999$ & 15 & 9 & 9 & 7 & 14 & 4 \\
$1999-2000$ & 36 & 11 & 1 & 2 & 1 & 36 \\
$2000-2001$ & 29 & 18 & 3 & 9 & 1 & 2 \\
$2001-2002$ & 29 & 14 & 5 & 16 & 3 & 5 \\
$2002-2003$ & 119 & 20 & 2 & 24 & 7 & 43 \\
$2003-2004$ & 123 & 28 & 4 & 36 & 5 & 5 \\
$2004-2005$ & 80 & 30 & 3 & 19 & 17 & 36 \\
\hline
\end{tabular}


growth rates calculated for a subset of corals obtained by excluding Favia and $S$. radians.

Mean yearly growth rates were displayed graphically for all juvenile corals, and separately for the most common genera. The goal was not to complete a statistical comparison among times (described in Edmunds 2004); rather it was to evaluate broad patterns of variation in growth rates among times and taxa. Histograms with $1 \mathrm{~mm} \mathrm{yr}^{-1}$ class intervals were used to display the frequency distributions of growth rates (pooled among years) in 4 size ranges of colonies: small $(\leq 10 \mathrm{~mm}$ diameter), medium $(\leq 20 \mathrm{~mm})$, large $(\leq 30 \mathrm{~mm})$ and extra large $(\leq 40 \mathrm{~mm})$. Finally, the relationship between growth $\left(\mathrm{mm} \mathrm{yr}^{-1}\right)$ and initial size was explored using scatterplots and Pearson correlations. Where a significant relationship was detected, reduced major axis (RMA) techniques were used to fit linear relationships, because the initial size and growth rates were measured with error and conformed to a Model II regression condition (Sokal \& Rohlf 1995, p. 544).

\section{RESULTS}

Over $9 \mathrm{yr}$, the growth of 1193 small corals was recorded (with some measured in multiple years), with the majority $\left(>79 \% \mathrm{yr}^{-1}\right)$ represented by Porites, Agaricia, Favia, Diploria, and Siderastrea radians. Of the corals tagged and remeasured over each year, 26 to $61 \%$ were Porites, 9 to $29 \%$ Agaricia, 1 to $27 \%$ Favia, 2 to $18 \%$ Diploria, and 1 to $29 \%$ S. radians; Porites was the most frequently tagged genus in 7 of the $9 \mathrm{yr}$, with Favia and $S$. radians each the most frequently tagged in one year. In every year, 14 to $28 \%$ of the tagged corals shrank, with the result that the overall (i.e. pooled among taxa and times) mean realized growth rate $\left(3.4 \pm 0.2 \mathrm{~mm} \mathrm{yr}^{-1} ; \pm \mathrm{SE}, \mathrm{n}=1193\right)$ was lower than the mean potential growth rate $\left(5.8 \pm 0.2 \mathrm{~mm} \mathrm{yr}^{-1}\right.$; $\pm \mathrm{SE}, \mathrm{n}=902$ ) (Table 2). The number of corals shrinking (with growth $<0 \mathrm{~mm} \mathrm{yr}^{-1}$ ) versus growing (i.e. categorized with growth $\geq 0 \mathrm{~mm} \mathrm{yr}^{-1}$ ) varied among taxa $\left(2 \times 3\right.$ contingency table, $\left.\chi^{2}=14.948, \mathrm{df}=4, \mathrm{p}=0.005\right)$, largely because of the relatively large number of Agaricia that shrank; and for Diploria, both the large number that grew, and the small number that shrank. Exclusion of $F$. fragum and $S$. radians from the analysis based on the rationale that some of their colonies were adults increased the mean realized and mean potential growth rates by $\leq 0.3 \mathrm{~mm} \mathrm{yr}^{-1}$, but this difference was not significant $(t \geq 0.693, \mathrm{df} \geq 1230, \mathrm{p} \geq 0.350$ ). The trend for greater potential compared to realized growth was evident every year, with the mean values for the 2 growth rates differing between $1.8 \mathrm{~mm} \mathrm{yr}^{-1}$ (in 1997 to 1998) and $4.4 \mathrm{~mm} \mathrm{yr}^{-1}$ (in 1998 to 1999) (Fig. 1). Overall, the growth rates of juvenile corals differed significantly among years $(F=13.439$, $\mathrm{df}=$ $8,2077, \mathrm{p}<0.001)$ and method of calculation (i.e. realized versus potential) $(F=74.338, \mathrm{df}=1,2077, \mathrm{p}<$ $0.001)$, but there was no statistical interaction between the two $(F=19.954$, df $=8,2077, \mathrm{p}=0.736)$.

For each taxon, the variation in growth rates among times and method of calculation were similar to the variation exhibited by all the taxa combined (Fig. 1). There was a significant interaction between time and taxon for the realized $(F=1.673, \mathrm{df}=28,981, \mathrm{p}=0.016)$ and the potential growth rates $(F=35.714, \mathrm{df}=28,710, \mathrm{p}=0.028)$, and therefore the growth of the dominant taxa responded in dissimilar ways to the conditions prevailing in each year. For example, while the realized growth rates for Siderastrea radians were higher in 2004 to 2005

Table 2. Growth rates (change in diameter, $\mathrm{mm} \mathrm{yr}^{-1}$ ) of juvenile corals in ${ }^{\mathrm{a}}$ the present study and ${ }^{\mathrm{b}-\mathrm{s}}$ from the literature. Values from the present study are grouped for all corals combined (i.e. pooled among taxa) and also for the most abundant taxa, and are displayed as realized and potential growth rates for the $9 \mathrm{yr}$ study; mean $\pm \mathrm{SE}_{i} \mathrm{n}=$ sample sizes. Values from the literature are listed either by taxon for Caribbean taxa, or when measurements were available from multiple taxa or from Indo-Pacific species, under 'All corals'. Studies $(\mathrm{a}-\mathrm{j})$ were completed in the Caribbean, and $(\mathrm{k}-\mathrm{s})$ in the Indo-Pacific. See Appendix 1

\begin{tabular}{|c|c|c|c|c|c|}
\hline \multirow[t]{2}{*}{ Taxon } & \multicolumn{4}{|c|}{$\begin{array}{l}- \text { Present study } \\
\text { Growth rate }\left(\mathrm{mm} \mathrm{yr}^{-1}\right)\end{array}$} & \multirow{2}{*}{$\begin{array}{l}\text { Other studies }{ }^{\mathrm{b}-\mathrm{s}} \\
\text { Growth rate } \\
\left(\mathrm{mm} \mathrm{yr}^{-1}\right)\end{array}$} \\
\hline & Realized & $\mathrm{n}$ & Potential & $\mathrm{n}$ & \\
\hline All corals & $3.4 \pm 0.2$ & 1193 & $5.8 \pm 0.2$ & 902 & $\begin{array}{l}10-11^{\mathrm{b}}, 10-34^{\mathrm{c}}, 11^{\mathrm{e}}, 6^{\mathrm{f}}, 5^{\mathrm{g}}, 4^{\mathrm{i}}, 4.9^{\mathrm{k}}, \\
9-12^{1}, 120^{\mathrm{m}}, 10^{\mathrm{n}}, 2^{\mathrm{o}}, 4-6^{\mathrm{p}}, \sim 25-40^{\mathrm{q}}, 13^{\mathrm{r}}, 7^{\mathrm{s}}\end{array}$ \\
\hline Porites & $3.7 \pm 0.3$ & 508 & $6.1 \pm 0.3$ & 381 & $17-29^{\mathrm{c}}, 3^{\mathrm{h}}, 12^{\mathrm{j}}$ \\
\hline Agaricia & $2.2 \pm 0.5$ & 177 & $5.2 \pm 0.4$ & 121 & $10-34^{\mathrm{c}}, 12-14^{\mathrm{d}}, 5^{\mathrm{h}}$ \\
\hline Favia & $2.1 \pm 0.5$ & 116 & $4.7 \pm 0.3$ & 81 & $12^{\mathrm{j}}$ \\
\hline Diploria & $5.3 \pm 0.6$ & 135 & $7.0 \pm 0.5$ & 116 & $7^{c}, 6^{h}$ \\
\hline Siderastrea radians & $1.7 \pm 0.4$ & 135 & $4.2 \pm 0.3$ & 93 & \\
\hline \multicolumn{6}{|c|}{ 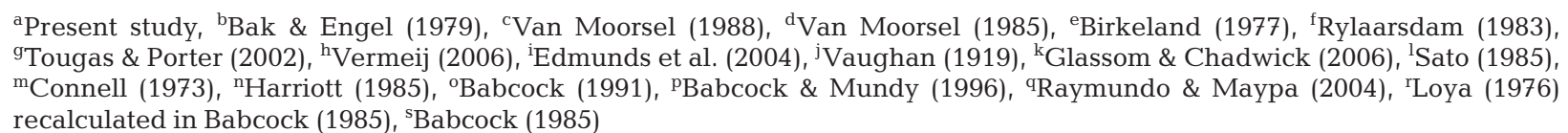 } \\
\hline
\end{tabular}




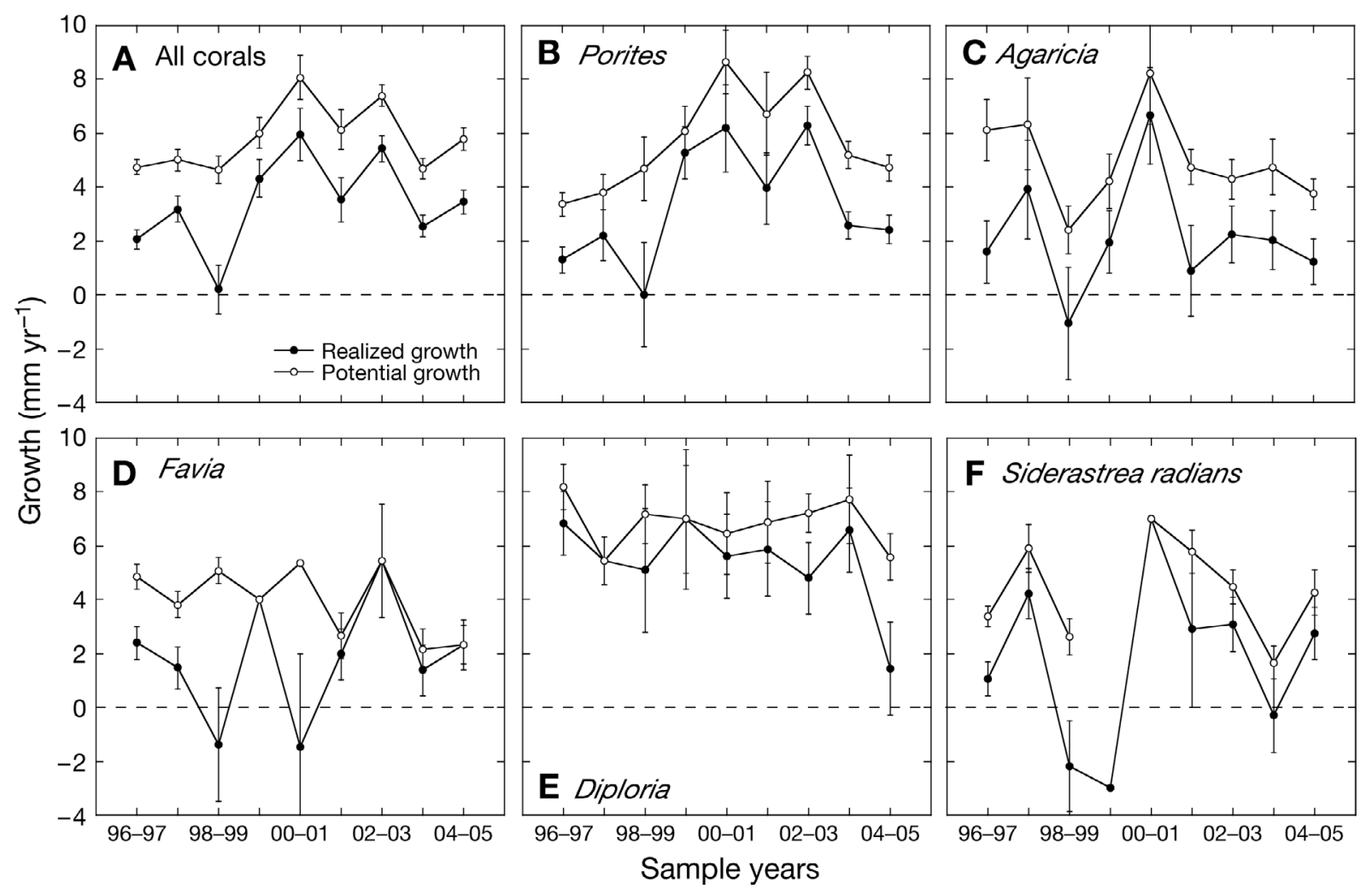

Fig. 1. Annual growth rates $\left(\mathrm{mm} \mathrm{yr}^{-1}\right)$ of juvenile corals on the shallow reefs $(<9 \mathrm{~m} \mathrm{depth})$ of St. John, US Virgin Islands, for $9 \mathrm{yr}$ between 1996 and 2005; results shown for both realized (•) and potential (O) growth rates. Values are presented for all coral combined (A) as well as the 5 taxa most frequently encountered (B-F). Mean \pm SE shown, with sample sizes ranging from 36 to 249 for 'All corals', 9 to 115 for Porites, 6 to 34 for Agaricia, 1 to 66 for Favia, 2 to 32 for Diploria and 1 to 58 for Siderastrea radians. For $S$. radians, the one coral measured over the 1999-2000 period shrank, and therefore there is no estimate of potential growth for this year, and the one measured over the 2000-2001 period increased in size, and therefore the potential and realized growth rates are the same. Horizontal dashed lines at $0 \mathrm{~mm} \mathrm{yr}^{-1}$ mark the transition from positive growth to shrinkage

compared with 2003 to 2004, the trend was reversed for Diploria (Fig. 1). Similarly, while the potential growth rates for Porites were higher in 1998 to 1999 compared with 1997 to 1998, the trend was reversed for Agaricia (Fig. 1). Notably, however, all of the corals together (i.e. pooled among taxa), as well as 4 of the 5 dominant taxa, exhibited the lowest realized growth in 1998 to 1999 (Fig. 1), which was the warmest year for surface seawater temperature in this location between 1990 and 2005 (Edmunds 2006), and since at least 1961 for the Caribbean as a whole (McWilliams et al. 2005). Over the 9 yr study period, however (i.e. pooling among years), both the realized and the potential growth rates differed significantly among taxa $(F=8.469, \mathrm{df}=4,1066, \mathrm{p}<$ 0.001 , and $F=6.322, \mathrm{df}=4,787, \mathrm{p}<0.001$, respectively), and in both cases, the growth rates for Diploria differed significantly from those for Agaricia, Favia and S. radians, and the growth rates for Porites differed significantly from those for $S$. radians (Bonferroni post-hoc comparisons, $\mathrm{p}<0.05$ ); no other contrasts were significant. Diploria grew faster than Agaricia, Favia and $S$. radians, and Porites grew faster than $S$. radians.
The realized growth rates for each taxon, pooled among the $9 \mathrm{yr}$, revealed a high degree of variation, even for corals that started at a similar size (Fig. 2). In general, this variability increased with size, but the trend was more pronounced for Porites and Agaricia than it was for other taxa. With Porites for example, while some colonies that started in the 30 to $40 \mathrm{~mm}$ size range grew 20 to $30 \mathrm{~mm}$, others shrank 10 to $20 \mathrm{~mm}$; but for colonies that started in the 5 to $10 \mathrm{~mm}$ size range, realized growth rates ranged from 0 to $10 \mathrm{~mm}$ $\mathrm{yr}^{-1}$ (Fig. 2). Even though realized growth rates varied greatly, they were correlated significantly with initial size for Porites $(\mathrm{r}=0.215, \mathrm{df}=506, \mathrm{p}<0.01)$, Favia $(\mathrm{r}=$ $-0.343, \mathrm{df}=116, \mathrm{p}<0.01)$ and Siderastrea radians $(\mathrm{r}=$ $-0.235, \mathrm{df}=232, \mathrm{p}<0.01$ ), but not for Agaricia or Diploria ( $\mathrm{p}>0.05)$. Interestingly, both Favia and S. radians, which display strong inverse relationships between size and realized growth, can achieve sexual maturity at $<40 \mathrm{~mm}$ diameter, while Porites grows faster at larger sizes compared to smaller sizes, but typically reaches sexual maturity at $>40 \mathrm{~mm}$ diameter (Soong 1991). 


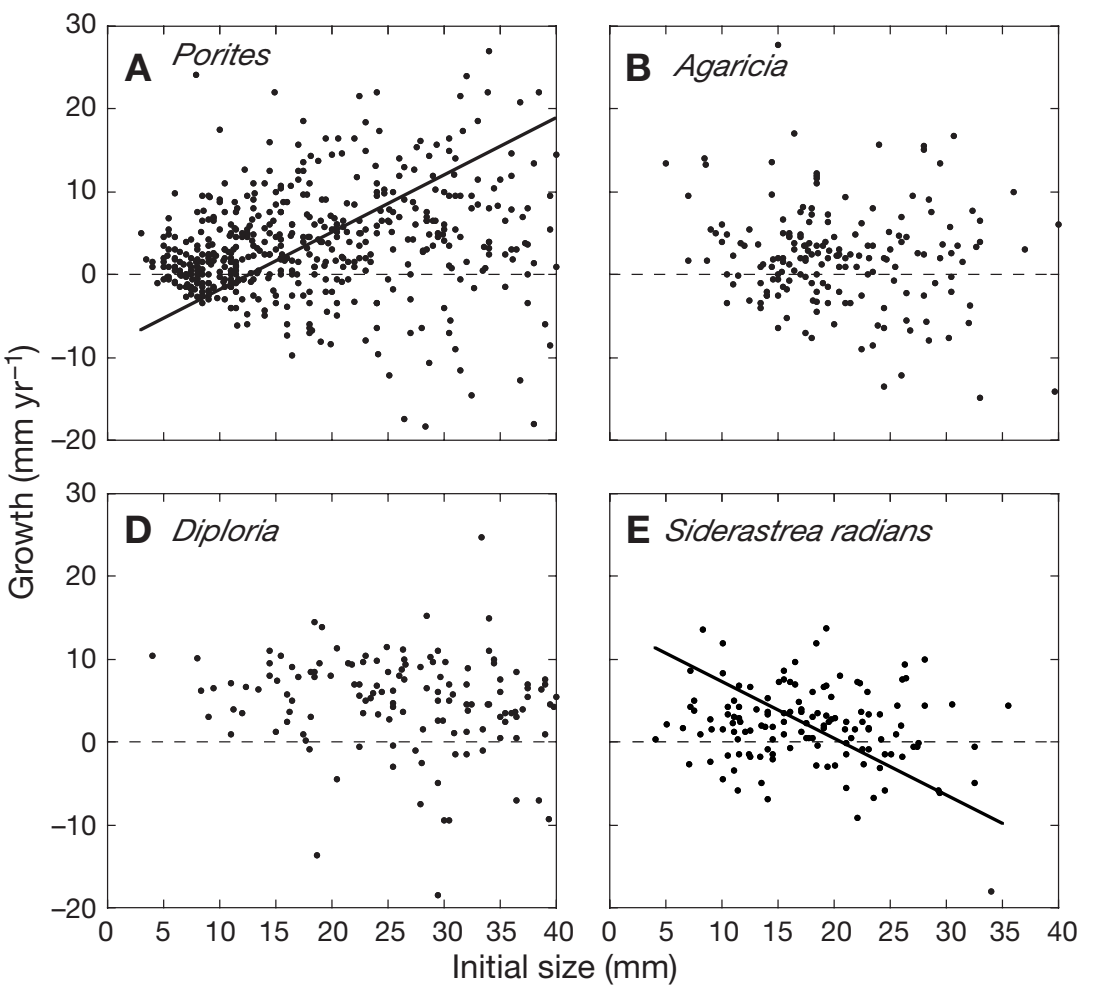

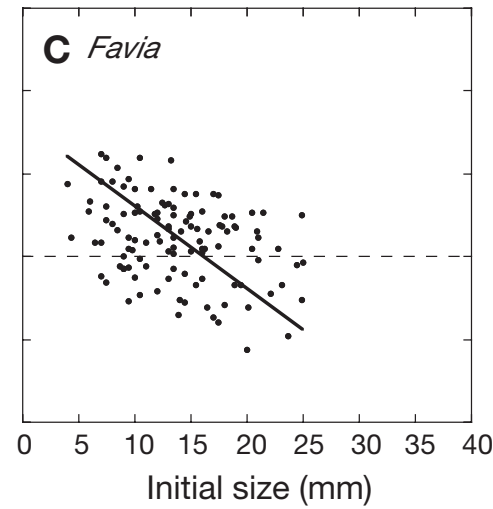

Fig. 2. Realized growth rates $\left(\mathrm{mm} \mathrm{yr}^{-1}\right)$ versus initial size for juvenile corals in St. John, pooled among years. Growth rates were significantly correlated with initial size for Porites, Favia and Siderastrea radians ( $\mathrm{p}<0.01$ ), but not for Agaricia or Diploria ( $\mathrm{p}>0.05)$; growth increased with size for Porites, but decreased with size for Favia and S. radians. Model II regression lines are displayed where correlations are significant; horizontal dashed lines at $0 \mathrm{~mm} \mathrm{yr}^{-1}$ mark the transition from positive growth to shrinkage
Even though the growth rates of the juvenile corals were variable (Figs. $1 \& 2$ ), a large number grew very slowly (i.e. $\leq 3 \mathrm{~mm} \mathrm{yr}^{-1}$ ), regardless of initial size. The strength of this trend is illustrated by histograms of the realized growth rates for each of 4 size ranges (Fig. 3). With the $1 \mathrm{~mm} \mathrm{yr}^{-1}$ resolution of the histograms, the modal growth rates were $1,2,2$, and $3 \mathrm{~mm} \mathrm{yr}^{-1}$ for juvenile corals categorized either as small $(\leq 10 \mathrm{~mm}$ initial diameter), medium ( $\leq 20 \mathrm{~mm})$, large $(\leq 30 \mathrm{~mm})$, or extra large $(\leq 40 \mathrm{~mm})$, respectively, and the mean growth rates in each of the categories were $\leq 5.2 \mathrm{~mm} \mathrm{yr}^{-1}$ (Fig. 3). Even when only the potential growth rates for each of the size classes were considered, the mean growth rates were $4 \mathrm{~mm} \mathrm{yr}^{-1}$ (from $75 \%$ of the small corals), $5 \mathrm{~mm} \mathrm{yr}^{-1}$ (from $76 \%$ of the medium corals), $6 \mathrm{~mm} \mathrm{yr}^{-1}$ (76\% of the large corals), and $8 \mathrm{~mm} \mathrm{yr}^{-1}$ (from $82 \%$ of the extra large corals) (Fig. 3). Qualitative analysis of the contribution of each of the 5 dominant taxa to these histograms, revealed that Porites contributed most to the structure of the distributions for all size classes, but also revealed subtle patterns that differed among size classes (Fig. 3). For instance, truncation of the lower tail of the distribution for the smallest corals was associated with a paucity of Agaricia and Siderastrea radians, both of which contributed substantially to the prominent lower tails of the distributions for the medium, large and extra large corals. Likewise, the higher abundance of Diploria in the large and extra large size classes, elevated both the mean growth rates and the size of the upper tail of the distributions (Fig. 3).
In comparison to the growth rates of juvenile corals that are reported in the literature, mostly for Caribbean corals, the growth rates reported here are low. This discrepancy is greatest for the realized growth rates, and the magnitude of the discrepancy varies among taxa (Table 2). For instance, in 2 often-cited studies of juvenile corals on Caribbean reefs, specifically those on the reefs of Curaçao and Bonaire in the late 1970 s and early 1980 s, growth rates in the range of 10 to $34 \mathrm{~mm} \mathrm{yr}^{-1}$ were reported for small colonies ( $\leq 40 \mathrm{~mm}$ diameter) (Bak \& Engel 1979, Van Moorsel 1985, 1988). In comparison, the mean realized and mean potential growth rates of all juvenile corals in St. John between 1996 and 2005 were 3.4 and $5.8 \mathrm{~mm}$ $\mathrm{yr}^{-1}$, respectively, and ranged from a low realized rate of $1.7 \mathrm{~mm} \mathrm{yr}^{-1}$ for Siderastrea radians, to a high potential rate of $7.0 \mathrm{~mm} \mathrm{yr}^{-1}$ for Diploria (Table 2).

A literature search revealed few studies in which the growth of juvenile corals was reported in a format comparable to the measurements presented here. Eighteen peer-reviewed studies were identified for the period 1919 to 2005 (listed in Table 2 and summarized in Appendix 1), and even in these cases the data were often difficult to obtain in a format comparable with the present data. Nevertheless, despite these limitations, a weak trend emerges suggesting that the growth of all juvenile corals (i.e. pooled among taxa) now is lower than it was $30 \mathrm{yr}$ ago (Fig. 4). Unfortunately, there were insufficient historic data to complete a similar analysis for individual genera, but for Porites 

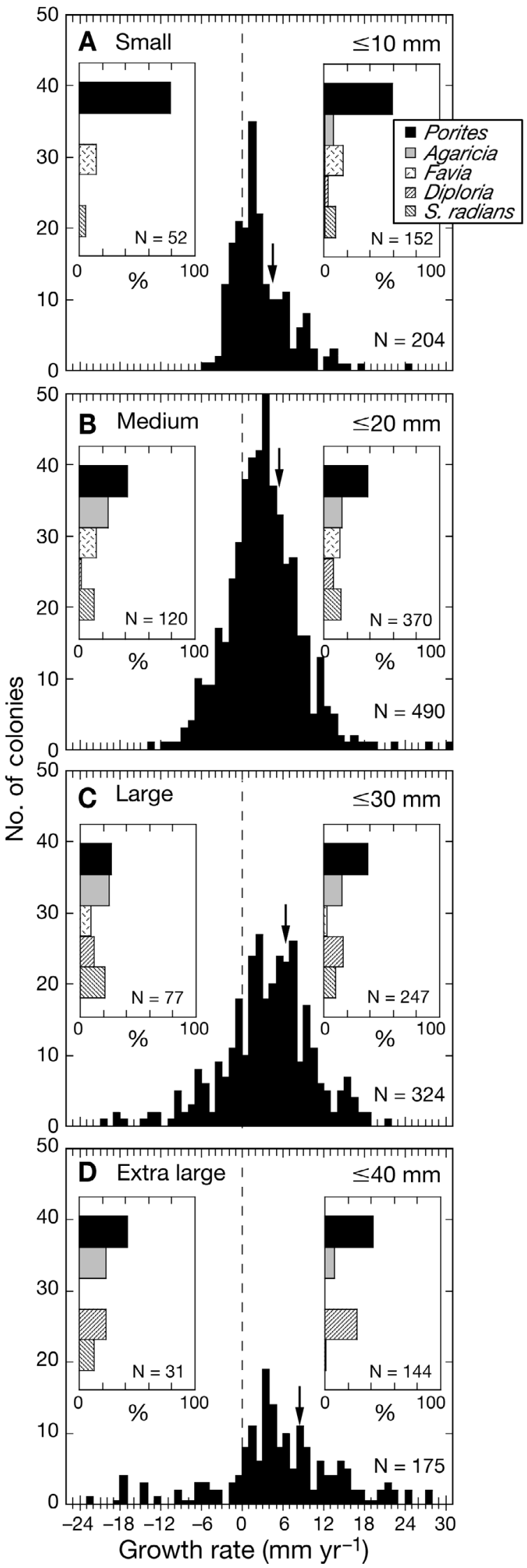

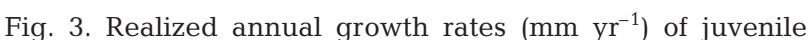
corals in St. John, pooled among years and taxa. Insets display the percentage contribution of the dominant taxa of juvenile corals (Porites, Agaricia, Favia, Diploria, Siderastrea radians) to the portions of the histograms that report shrinkage (rates $<0 \mathrm{~mm} \mathrm{yr}^{-1}$, left insets) and potential growth (rates $\geq 0 \mathrm{~mm} \mathrm{yr}^{-1}$, right insets). Growth rates are divided into $1 \mathrm{~mm} \mathrm{yr}^{-1}$ classes, and separated by initial colony size into (A) small $(\leq 10 \mathrm{~mm}$ diameter), (B) medium ( $\leq 20 \mathrm{~mm})$, (C) large $(\leq 30 \mathrm{~mm})$, or (D) extra large $(\leq 40 \mathrm{~mm})$ colonies. The mean growth rates $( \pm \mathrm{SE})$ for small, medium, large and extra large colonies were $2.6 \pm$ $0.3,3.0 \pm 0.2,3.5 \pm 0.4$, and $5.2 \pm 0.7 \mathrm{~mm} \mathrm{yr}^{-1}$, and their modal growth rates were $1,2,2$, and $3 \mathrm{~mm} \mathrm{yr}^{-1}$, respectively. The vertical dashed lines mark the break between shrinkage and growth, and the vertical arrows show the mean potential

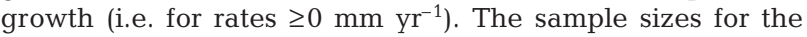
inset plots are shown within the box frames, and the 2 values for each inset graph sum to the sample size for the histogram to which they apply

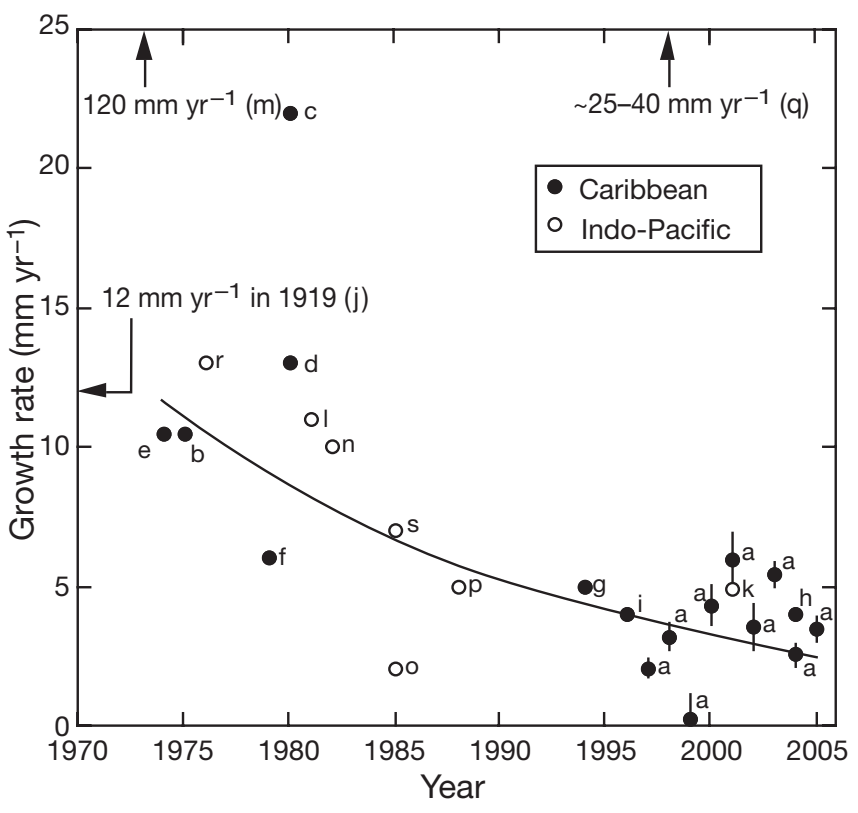

Fig. 4. Growth rates $\left(\mathrm{mm} \mathrm{yr}^{-1}\right)$ of juvenile corals over a $32 \mathrm{yr}$ period (beginning in 1973), based on results from multiple locations in the Caribbean $(\bullet)$ and Indo-Pacific $(0)$. Data were obtained from the present study $(a$; realized growth rates, pooled by taxa) as well as 18 peer-reviewed publications (b-s, see Table 2, Appendix 1) that reported growth rates for juvenile corals growing in habitats ranging from reef flats to $30 \mathrm{~m}$ depth. Means \pm SE are reported for the results from the present study; for studies from which a range of values was obtained (b, c, d, l, p, h), the extreme values were averaged for graphical display and curve fitting. The 2 vertical arrows mark the results from 2 studies ( $\mathrm{m}$ and $\mathrm{q}$ ) reporting high growth rates (i.e. $\geq 50 \mathrm{~mm} \mathrm{yr}^{-1}$ ) from Indo-Pacific reefs, the horizontal arrow marks the result for one study from 1919 (j); none of these values can readily be shown on a graph with linear axes, and were not used in the calculation of the best-fit relationship. The curve is the best-fit exponential relationship $\left(\mathrm{r}^{2}=\right.$ 0.716 ) to all of the data (Caribbean and Indo-Pacific combined), and has the equation $y=\left(3.561 \times 10^{43}\right) \times \mathrm{e}^{-0.0496 x}$ 
(the best represented genus) the few available data are consistent with a decline in growth rates from 9 to 12 mm yr ${ }^{-1}$ before 1981 (Vaughan 1919, Rylaarsdam 1983, Van Moorsel 1988) to $4 \mathrm{~mm} \mathrm{yr}^{-1}$ between 1996 and 2005 (Table 2).

\section{DISCUSSION}

The purposes of this study were to provide a comprehensive analysis of the growth of juvenile corals in order to facilitate a comparison with historic data and resolve temporal and taxonomic variation in this trait. The larger objective, to improve the understanding of the causal basis of the trajectories of change in present-day coral communities (Knowlton 2001, Gardner et al. 2003, Bellwood et al. 2004), relies on the assumption that the growth of juvenile corals affects the demographics of reef corals, which is true to the extent that colonies are added to the population by sexual recruitment. Before this study was completed, it was expected that the growth rates of juvenile corals in St. John would fall in the upper range of possible values as determined from the literature, firstly because the study reefs are in shallow water $(<9 \mathrm{~m}$ depth) where high irradiances promote coral calcification (Barnes \& Chalker 1990), and secondly, because they are protected by their inclusion within a marine protected area (Rogers \& Beets 2001) from some disturbances that can depress the growth of corals. In contrast to this expectation, nearly a decade of data revealed that the growth rates of juvenile corals consistently were lower than many values that previously have been reported, particularly those appearing before 1990 (Table 2).

Good examples of this discrepancy come from a contrast of the growth rates for juvenile corals in St. John with those reported in the late 1970s and early 1980s from Curaçao and Bonaire (i.e. 10 to $34 \mathrm{~mm} \mathrm{y}^{-1}$, Bak \& Engel 1979, Van Moorsel 1985, 1988). Differences in methodology, location, depth, and species make such comparisons difficult to evaluate-particularly since the early work of Van Moorsel (1985) focused on maximum (not average) growth rates-but nevertheless, the contrast suggests that juvenile corals in St. John currently grow at 10 to $34 \%$ of the rates predicted from studies completed $\geq 25$ yr ago (based on contemporary realized growth rates of $3.4 \mathrm{~mm} \mathrm{yr}^{-1}$ ). Although comparative data are rare, a similar conclusion can be reached through a broader comparison with other studies completed in the Caribbean and Pacific (Table 2). While a different conclusion might be reached through an explicit contrast with juvenile corals of branching species, which typically grow faster than massive species (Buddemeier \& Kinzie 1976, Babcock 1985) and are common on Pacific reefs (Veron 1986), on
Caribbean reefs, juvenile colonies of massive and encrusting corals (as recorded here) have dominated recruiting coral populations for decades (Bak \& Engel 1979, Rogers et al. 1984), as well as the few studies that have recorded their growth (references in Table 2).

To evaluate the significance of the discrepancy between present and historic growth rates of juvenile corals, it is important first, to consider the legitimacy of the discrepancy and its influence on the field of coral reef ecology, and second, to identify mechanisms that might lead to this discrepancy. Clearly, the growth rates of juvenile corals in St. John are lower than historic values (Table 2), but unfortunately the paucity of data makes it impossible to know whether this is a generalized pattern or whether it simply reflects population dynamics that vary regionally (among islands), temporally (e.g. Fig. 1), or as a result of a combination of the 2 factors. There is evidence however, that the present results are not simply outliers within a larger spatio-temporal scale, because results from contemporary reefs show that juvenile corals grow at $\sim 3$ to $7 \mathrm{~mm} \mathrm{yr}^{-1}$ in at least 4 locations: the US Virgin Islands (present study), the Florida Keys (Edmunds et al. 2004), Curaçao (Vermeij 2006), and the Red Sea (Glassom \& Chadwick 2006). Thus, it is difficult to dismiss the slow growth rates of juvenile corals in St. John as a location-specific phenomenon, attributed perhaps to the granitic substratum that is common subtidally in St. John but rare in most Caribbean locations. In addition to the consistency of growth rates for juvenile corals on contemporary reefs in at least 4 locations, the growth rates in St. John have been 'low' for nearly a decade (Fig. 1), although they have varied substantially among years (Fig. 1) in a pattern that is associated with seawater temperature (Edmunds 2004, 2006), notably with the majority of the lowest realized growth rates occurring in the warmest year on record (Edmunds 2006). While the growth rates of juvenile corals in St. John differ among genera in both magnitude (Table 2, Fig. 1) and the dependency on colony size (Fig. 2; see Vermeij 2006), it is unlikely that taxonomic artifacts can account for the slow growth of juvenile corals in this location. Most importantly in this regard, the potential for taxonomic effects (which can be substantial, Fig. 1) to bias the present interpretation is reduced by the consistent dominance of the sampled corals by a few genera that are the same genera that have dominated virtually all previous studies of juvenile corals in the Caribbean (Bak \& Engel 1979, Rogers et al. 1984, Smith 1992, Chiappone \& Sullivan 1996). Although Favia fragum and Siderastrea radians represent special cases in terms of evaluating growth rates of juvenile corals, mostly because they can be sexually mature when small (Soong 1991) and display inverse size-dependency of growth (Fig. 2), whether or not 
they were included in the calculations of mean realized and potential growth rates had no significant effect on the outcome.

If the slow growth of juvenile corals in St. John is characteristic of at least a subset of contemporary reefs, then it is appropriate to evaluate the implications of downwardly revising what is recognized as 'representative' for the growth rates of small corals. One aspect of this evaluation is characterizing the biological context that has been created by the results of previous studies. Although this context is surprisingly poorly informed, there are signs of a strong influence on current scientific thinking from historic studies such as those of Bak \& Engel (1979) and Van Moorsel (1985, 1988). For instance, Rogers et al. (1984), Chiappone \& Sullivan (1996), and Moulding (2005), all assumed that juvenile corals grow at 12 to $36 \mathrm{~mm} \mathrm{yr}^{-1}$ in their analyses of coral recruitment in the Virgin Islands and Florida Keys; and for Sprecher et al. (2003), the assertion that juvenile corals settled soon after a bleaching event in the Maldive Islands was predicated on them growing at the high rates attributed to Bak \& Engel (1979). Similarly, Edmunds \& Carpenter (2001) relied on juvenile corals growing at $\sim 12 \mathrm{~mm} \mathrm{yr}^{-1}$ in Jamaica in order to establish temporal concordance between the population recovery of the echinoid Diadema antillarum and increased rates of coral recruitment. Although Bak \& Engel (1979) actually did not measure growth rates of 12 to $36 \mathrm{~mm} \mathrm{yr}^{-1}$ (their only measured rates are 10 to $11 \mathrm{~mm} \mathrm{yr}^{-1}$ for Agaricia), Van Moorsel (1985, 1988) demonstrated empirically that juvenile corals in the same location could indeed grow rapidly (10 to $34 \mathrm{~mm} \mathrm{yr}^{-1}$ ), particularly in comparison to contemporary growth rates for corals in a similar size range.

The biological significance of slower growth rates for juvenile corals is determined largely by the effects on the longevity of this life stage, which are inversely proportional to growth rates. Important consequences of upwardly revising the duration of the juvenile life stage include a greater chance of dying as a result of a longer exposure to the high annualized mortality rates of small corals (Jackson 1977, Edmunds \& Gates 2004), as well as a slowing of the tempo of coral recovery through recruitment following a disturbance event. In other words, fewer recruits will survive to an adult stage if they grow more slowly, and those that become adults will have spent longer in the juvenile stage. Therefore, the rate at which a coral reef recovers following the mitigation of deleterious conditions, such as currently appears to be occurring in the Caribbean as populations of the echinoid Diadema antillarum recover (Edmunds \& Carpenter 2001, Carpenter \& Edmunds 2006), may be slower than is believed at present. These effects will be accentuated when recruitment rates are depressed, as occurs on de- graded reefs (Hughes \& Tanner 2000, Bellwood et al. 2004), but the ultimate effects on population growth will be determined by multiple factors including both recruitment and the growth and survival of existing coral colonies (Hughes \& Tanner 2000, Edmunds \& Elahi 2007).

Although there is much uncertainty regarding the mechanism driving the present results for juvenile growth, notably whether the discrepancy with previous studies represents a real change in performance or simply a data-driven readjustment of the consensus opinion (discussed below), the implications described above for coral population dynamics are unchanged. It is worth noting however, that the growth of juvenile corals vary greatly within a year as shown by the scatter of data in Figs. 2 \& 3, and as reported previously by some of the few authors that have studied this topic (e.g. Babcock 1985, Vermeij 2006), most notably by Van Moorsel (1988), whose study focused on maximal growth of juvenile corals. Evidence from the present study suggests that such differences are deterministic (rather than random) because for the juvenile corals that were scored in multiple years, growth rates in one year were associated significantly and positively with the growth rates in the subsequent year (author's unpubl. data). In contrast, however, in Curaçao the growth of coral recruits in one year was not a good predictor of growth in the subsequent year (Vermeij 2006), suggesting that the variation in growth was more random than deterministic. Such variation in growth rates should be studied further, because the extent to which the growth of coral recruits is deterministic has important implications for understanding how recruitment modulates population-level processes. Importantly, strong among-colony variation in growth of juvenile corals could provide a tractable experimental system to gain insight into fundamental questions such as how natural selection determines which recruits survive, and how evolutionary processes shape the response of coral communities to changing environmental conditions.

Mensurative analyses such as described here cannot 'explain' spatio-temporal trends in coral growth or identify cause-and-effect relationships, both of which remain in the domain of manipulative experimentation. However, if the slow growth of juvenile corals in St. John is unlikely to be a result of regional artifacts or temporal anomalies, then presumably there must be some other mechanistic basis to these findings. Currently, such mechanisms are a matter of speculation, but one possibility, that contemporary reefs in shallow water differ from historic reefs in terms of the growth opportunities for juvenile corals, deserves immediate attention. Two prominent ways that contemporary reefs may differ from historic reefs, at least in shallow 
Caribbean waters, is in terms of seawater temperature, which is $0.7^{\circ} \mathrm{C}$ warmer in the Virgin Islands now than 30 yr ago (calculated from the data presented in Sheppard \& Rioja-Niteo 2005, see also Edmunds 2006), and the aragonite saturation state $\left(\Omega_{a}\right)$, which is thought to have declined $13 \%$ from historic values, due to rising atmospheric $\mathrm{CO}_{2}$ levels (Kleypas et al. 1999).

Coral growth (i.e. calcification) and temperature are related with a complex curvilinear response (Buddemeier \& Kinzie 1976, Reynaud-Vaganay et al. 1999, Edmunds 2005), and beyond a threshold value growth declines rapidly with rising temperature (Edmunds 2005) and thereby potentially explaining why growth rates of juveniles now appear depressed compared to the $1970 \mathrm{~s}$ and $1980 \mathrm{~s}$. There is inadequate data to test this hypothesis for Caribbean corals, but for pocilloporids from the southern Great Barrier Reef, an increase from 29.0 to $29.7^{\circ} \mathrm{C}$ would decrease growth rates (mass deposition of aragonite) by $26 \%$, although this outcome is strongly dependent on the initial temperature because of the shape of the growthtemperature response (Edmunds 2005). Interestingly, previous results from St. John already suggest that the growth of juvenile corals is inversely related to seawater temperature, at least in the 12 to 24 mo period prior to growth occurring and over a relatively short period between 1996 and 2001 (Edmunds 2004). Declining $\Omega_{\mathrm{a}}$ also has a strong effect on coral growth (Langdon 2000), and potentially could contribute to growth reductions for juvenile corals. However, the decline in $\Omega_{\mathrm{a}}$ that has taken place over the last century is thought to have reduced coral growth by only 6 to $11 \%$ (Kleypas et al. 1999), and therefore the potential effects over the last 30 yr would be small, particularly in relation to the putative decline in linear growth of juvenile corals. Augmenting these potential effects of abiotic factors are the consequences of extensive growths of benthic algae, which now dominate many Caribbean reefs (Hughes 1994, McCook 1999, Knowlton 2001) and can impede coral growth through direct competition for space (Jompa \& McCook 2002). Elucidating how these putative mechanisms act in concert to depress the growth of juvenile corals in St. John is a research priority, because the results have considerable relevance to evaluating the consequences of further environmental degradation on the success of reef corals.

Acknowledgements. This research was supported by the Long Term Research in Environmental Biology program of the US National Science Foundation (DEB 0343570), with additional funding provided by the Sea Grant Program of the University of Puerto Rico (\#R-101-2-02), California State University, Northridge, and the Virgin Islands National Park. The fieldwork would have been impossible without the assistance of my graduate students, or the support provided in St. John by the Virgin Islands National Park, R. Boulon, and C. S.
Rogers. I thank S. Prosterman for scuba support, V. Powell for on-site logistics, and the staff of the Virgin Islands Environmental Resource Station for making our visits enjoyable and productive. Comments from R. C. Carpenter, M. Maheigan, N. Muehllehner, H. Putnam and 3 anonymous reviewers improved an earlier draft of this paper. This is contribution no. 144 of the CSUN marine biology program.

\section{LITERATURE CITED}

Babcock RC (1985) Growth and mortality in juvenile corals (Goniastrea, Platygyra and Acropora): the first year. Proc 5th Int Coral Reef Symp 4:355-360

Babcock RC (1991) Comparative demography of three species of scleractinian corals using age- and size-dependent classifications. Ecol Monogr 61:225-244

Babcock R, Mundy C (1996) Coral recruitment: consequences of settlement choice for early growth and survivorship in two scleractinians. J Exp Mar Biol Ecol 206:179-201

Bak RPM, Engel MS (1979) Distribution, abundance and survival of juvenile hermatypic corals (Scleractinia) and the importance of life history strategies in the parent community. Mar Biol 54:341-352

Barnes DJ, Chalker BE (1990) Calcification and photosynthesis in reef-building corals and algae. In: Dubinsky Z (ed) Ecosystems of the world, Vol 25, Coral Reefs. Elsevier, New York, p 109-131

Bellwood DR, Hughes TP, Folke C, Nystrom M (2004) Confronting the coral reef crisis. Nature 429:827-833

Birkeland C (1977) The importance of rate of biomass accumulation in early successional stages of benthic communities to the survival of coral recruits. Proc 3rd Int Coral Reef Symp 1:15-21

Buddemeier RW, Kinzie RA (1976) Coral growth. Ocean Mar Biol Ann Rev 14:183-225

Caley MJ, Carr MH, Hixon MA, Hughes TP, Jones GP, Menge BA (1996) Recruitment and the local dynamics of open marine populations. Ann Rev Ecol Syst 27: $477-500$

Carpenter RC, Edmunds PJ (2006) Local and regional scale recovery of Diadema promotes recruitment of scleractinian corals. Ecol Lett 9:271-280

Caswell H (2001) Matrix population models. Sinauer Associates, Sunderland, MA

Chiappone M, Sullivan KM (1996) Distribution, abundance and species composition of juvenile scleractinian corals in the Florida reef tract. Bull Mar Sci 58:555-569

Connell JH (1973) Population ecology of reef-building corals. In: Jones OA, Endean R (eds) Biology and geology of coral reefs, Vol 2. Academic Press, New York, p 205-245

Connell JH (1978) Diversity in tropical rain forests and coral reefs. Science 199:1302-1310

Connell JH (1997) Disturbance and recovery of coral assemblages. Proc 8th Int Coral Reef Symp 1:9-22

Dunstan PK, Johnson CR (1998) Spatio-temporal variation in coral recruitment at different scales on Heron Reef, southern Great Barrier Reef. Coral Reefs 17:71-81

Edmunds PJ (2000) Patterns in the distribution of juvenile corals and coral reef community structure in St. John, US Virgin Islands. Mar Ecol Prog Ser 202:113-124

Edmunds PJ (2002) Long-term dynamics of coral reefs in St. John, US Virgin Islands. Coral Reefs 21:357-367

Edmunds PJ (2004) Juvenile coral population dynamics track rising seawater temperature on a Caribbean reef. Mar Ecol Prog Ser 269:111-119

Edmunds PJ (2005) The effect of sub-lethal increases in tem- 
perature on the growth and population trajectories of three scleractinian corals on the southern Great Barrier Reef. Oecologia 146:350-364

Edmunds PJ (2006) Temperature-mediated transitions between isometry and allometry in a colonial, modular invertebrate. Proc R Soc Ser B 273:2275-2281

Edmunds PJ, Carpenter RC (2001) Recovery of Diadema antillarum leads to reduced macroalgal cover and increased abundance of juvenile corals on a Caribbean reef. Proc Natl Acad Sci USA 98:5067-5071

Edmunds PJ, Elahi R (2007) The demographics of a 15-year decline in cover of the Caribbean reef coral Montastraea annularis. Ecol Monogr 17:3-18

Edmunds PJ, Gates RD (2004) Size-dependent differences in the physiology of the reef coral Porites astreoides. Biol Bull 206:61-64

Edmunds PJ, Bruno JF, Carlon DB (2004) Effects of depth and microhabitat on growth and survivorship of juvenile corals in the Florida Keys. Mar Ecol Prog Ser 278:115-124

Fong P, Glynn PW (1998) A dynamic size-structure population model: does disturbance control size structure of a population of the massive coral Gardinoseris planulata in the Eastern Pacific. Mar Biol 130:663-674

Gardner TA, Coté IM, Gill JA, Grant A, Watkins AR (2003) Long-term, region-wide declines in Caribbean corals. Science 301:958-960

Gardner TA, Coté IM, Gill JA, Grant A, Watkins AR (2005) Hurricanes and Caribbean coral reefs: impacts, recovery patterns, and role in long-term decline. Ecology 86: $174-184$

Glassom D, Chadwick NE (2006) Recruitment, growth and mortality of juvenile corals at Eilat, northern Red Sea. Mar Ecol Prog Ser 318:111-122

Gosselin LA, Qian PY (1997) Juvenile mortality in benthic marine invertebrates. Mar Ecol Prog Ser 146:265-282

Harriott VJ (1985) Recruitment patterns of scleractinian corals at Lizard Island, Great Barrier Reef. Proc 5th Int Coral Reef Symp 4:367-372

Harrison PL, Wallace CC (1990) Reproduction, dispersal and recruitment of scleractinian corals. In: Dubinsky Z (ed) Ecosystems of the world, Vol 25, Coral Reefs. Elsevier, New York, p 133-207

Highsmith RC (1982) Reproduction by fragmentation in corals. Mar Ecol Prog Ser 7:207-226

Hughes TP (1984) Population dynamics based on individual size rather than age: a general model with a reef coral example. Am Nat 123:778-795

Hughes TP (1994) Catastrophies, phase shifts, and large-scale degradation of a Caribbean coral reef. Science 265: $1547-1551$

Hughes TP, Tanner JE (2000) Recruitment failure, life histories, and long-term decline of Caribbean corals. Ecology 81:2250-2263

Hughes TP, Baird AH, Dinsdale EA, Moltschaniwskyj NA, Pratchett MS, Tanner JE, Willis BL (1999) Patterns of recruitment and abundance of corals along the Great Barrier Reef. Nature 397:59-63

Hughes TP, Baird AH, Bellwood DR, Card M and 12 others (2003) Climate change, human impacts, and the resilience of coral reefs. Science 301:929-933

Hunt HL, Sheibling RE (1997) Role of early post-settlement morality in recruitment of benthic marine invertebrates. Mar Ecol Prog Ser 155:269-301

Hunter CL, Evans CW (1995) Coral reefs in Kaneohe Bay, Hawaii: two centuries of western influence and two decades of data. Bull Mar Sci 57:501-515

Jackson JBC (1977) Competition on marine hard substrata: the adaptive significance of solitary and colonial strategies. Am Nat 980:743-767

Jompa J, McCook LJ (2002) Effects of competition and herbivory on interactions between a hard coral and a brown algal. J Exp Mar Biol Ecol 271:25-39

Karlson RH, Hurd LE (1993) Disturbance, coral reef communities, and changing ecological paradigms. Coral Reefs 12: $117-125$

Kleypas JA, Buddemeier RW, Archer D, Gattuso JP, Langdon C, Opdyke BN (1999) Geochemical consequences of increased carbon dioxide on coral reefs. Science 284: $118-120$

Knowlton N (2001) The future of coral reefs. Proc Natl Acad Sci USA 98:5419-5425

Langdon C (2000) Review of experimental evidence for effects of $\mathrm{CO}_{2}$ on calcification of reef builders. Proc 9th Int Coral Reef Symp 2:1091-1098

Loya Y (1976) Settlement, mortality, and recruitment of a Red Sea scleractinian coral population. In: Mackie GO (ed) Coelenterate ecology and behavior. Plenum Press, New York, p 89-100

McCook LJ (1999) Macroalgae, nutrients and phase shifts on coral reefs: scientific issues and management consequences for the Great Barrier Reef. Coral Reefs 18:357-367

McWilliams JP, Cote IM, Gill JA, Sutherland WJ, Watkinson AR (2005) Accelerating impacts of temperature-induced coral bleaching in the Caribbean. Ecology 86:2055-2060

Morgan SG (2001) The larval ecology of marine communities. In: Bertness MD, Gaines SD, Hay ME (eds) Marine community ecology. Sinauer Associates, Sunderland, MA, p 159-181

Moulding AL (2005) Coral recruitment patterns in the Florida Keys. Rev Biol Trop 53:75-82

Nystrom M, Folke C, Moberg F (2000) Coral reef disturbance and resilience in a human-dominated environment. Trends Ecol Evol 15:413-417

Pearson RG (1974) Recolonization by hermatypic corals of reefs damaged by Acanthaster. Proc 2nd Int Coral Reef Symp 2:207-215

Pearson RG (1981) Recovery and recolonization of coral reefs. Mar Ecol Prog Ser 4:105-122

Raymundo LJ, Maypa AP (2004) Getting bigger faster: mediation of size-specific mortality via fusion in juvenile coral transplants. Ecol Appl 14:281-295

Reynaud-Vaganay S, Gattuso JP, Cuif JP, Jaubert J, JuilletLeclerc A (1999) A novel culture technique for scleractinian corals: application to investigate changes in skeletal $\delta^{18} \mathrm{O}$ as a function of temperature. Mar Ecol Prog Ser 180: 121-130

Richmond RH (1997) Reproduction and recruitment in corals: critical links in the persistence of reefs. In: Birkeland C (ed) Life and death of coral reefs. Chapman \& Hall, New York, p 175-197

Rogers CS, Beets J (2001) Degradation of marine ecosystems and decline of fishery resources in marine protected areas in the US Virgin Islands. Environ Conserv 28:312-322

Rogers CS, Miller J (2006) Permanent 'phase shifts' or reversible declines in coral cover? Lack of recovery of two coral reefs in St. John, US Virgin Islands. Mar Ecol Prog Ser 306:103-114

Rogers CS, Fitz HC, Gilnack M, Beets J, Hardin J (1984) Scleractinian coral recruitment patterns at Salt River Submarine Canyon, St. Croix, US Virgin Islands. Coral Reefs 3:69-76

Rylaarsdam KW (1983) Life histories and abundance patterns of colonial corals on Jamaican reefs. Mar Ecol Prog Ser 13:249-260 
Sato M (1985) Mortality and growth of juvenile coral Pocillopora damicornis (Linnaeus). Coral Reefs 4:27-33

Sebens KP (1981) The allometry of feeding, energetics, and body size in three sea anemone species. Biol Bull 161: 152-171

Sheppard C, Rioja-Nieto R (2005) Sea surface temperature 1871-2099 in 38 cells in the Caribbean region. Mar Environ Res 60:389-396

Smith SR (1992) Patterns of coral recruitment and post-settlement mortality on Bermuda's reefs: comparisons to Caribbean and Pacific reefs. Am Zool 32:663-673

Smith SR (1997) Patterns of coral settlement, recruitment, and juvenile mortality with depth at Conch Reef, Florida. Proc 8th Int Coral Reef Symp 2:1197-1202

Sokal RR, Rohlf FJ (1995) Biometry. Freeman, New York

Soong K (1991) Sexual reproduction patterns of shallowwater reef corals in Panama. Bull Mar Sci 49:832-846

Sprecher SG, Galle S, Reichert H (2003) Substrate specificity and juvenile Faviid predominance of coral colonization at the Maldive Islands following the 1998 bleaching event. Coral Reefs 22:130-132

Thorson G (1950) Some factors influencing the recruitment and establishment of marine benthic invertebrates. Neth J Sea Res 3:267-293

Tougas JI, Porter JW (2002) Differential coral recruitment patterns in the Florida Keys. In: Porter JW, Porter KG (eds)
The Everglades, Florida Bay, and coral reefs of the Florida Keys: an ecosystem sourcebook. CRC Press, Boca Raton, FL, p 789-811

Underwood AJ, Keough MJ (2001) Supply-side ecology: the nature and consequences of variations in recruitment of intertidal organisms. In: Bertness MD, Gaines SD, Hay ME (eds) Marine community ecology. Sinauer Associates, Sunderland, MA, p 183-200

Van Moorsel GWNM (1985) Disturbance and growth of juvenile corals (Agaricia humilis and Agaricia agaraicites, Scleractinia) in natural habitats on the reef of Curaçao. Mar Ecol Prog Ser 24:99-112

Van Moorsel GWNM (1988) Early maximum growth of stony corals (Scleractinia) after settlement of artificial substrata on a Caribbean reef. Mar Ecol Prog Ser 50:127-135

Vaughan TW (1919) Corals and the formation of coral reefs. Smithsonian Inst Ann Rep 189-238

Vermeij MJA (2006) Early life-history dynamics of Caribbean coral species on artificial substratum: the importance of competition, growth and variation in life-history. Coral Reefs 25:59-71

Veron JEN (1986) Corals of Australia and the Indo-Pacific. University of Hawaii, Honolulu, HI

Wittenberg M, Hunte W (1992) Effects of eutrophication and sedimentation on juvenile corals. I. Abundance, mortality and community structure. Mar Biol 112:131-138 


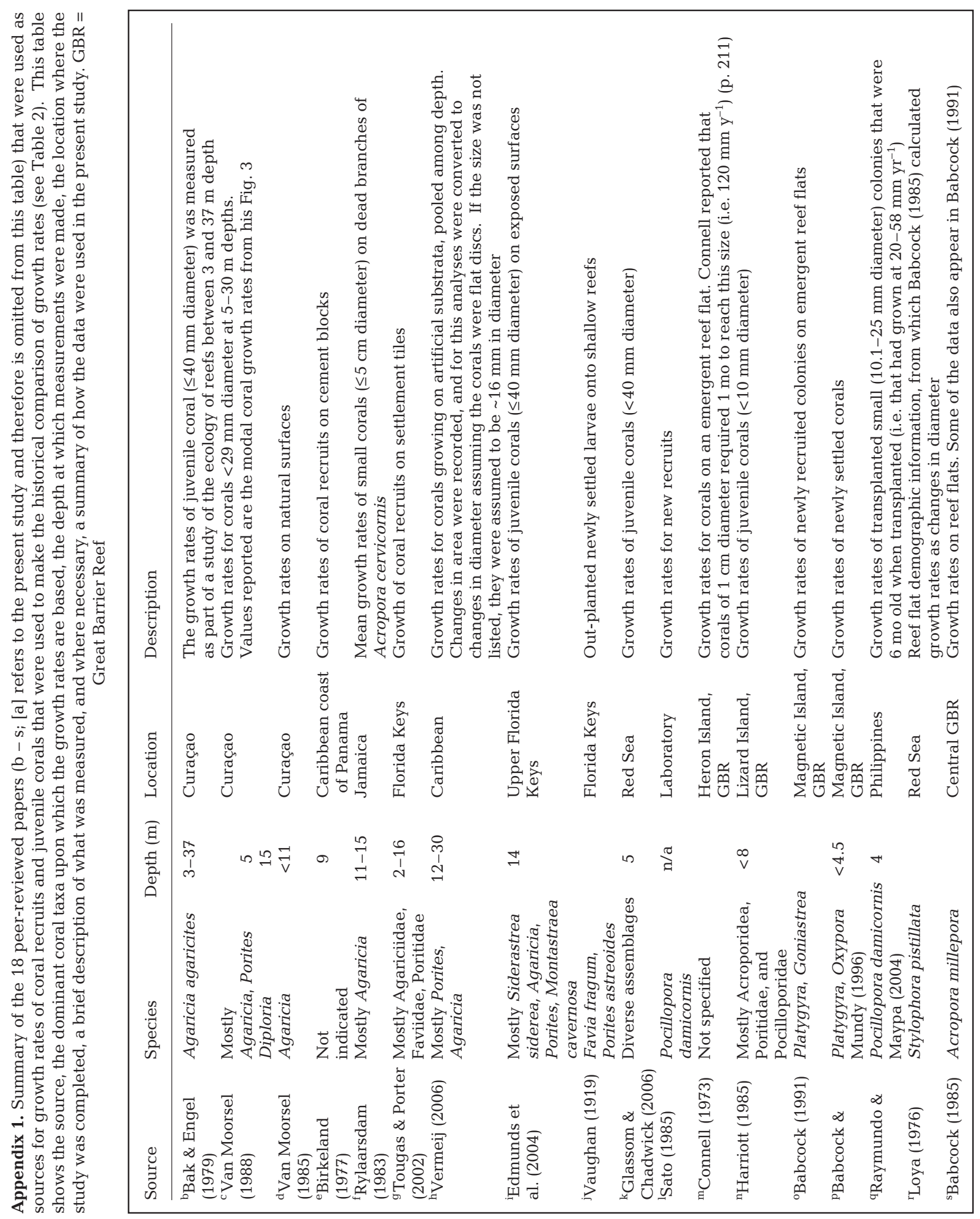

